\title{
Do student demographics and country location affect the international learning experience of nursing students?
}

\author{
Susan Ka Yee Chow*1, Keith Hin Kee Fung ${ }^{2}$ \\ ${ }^{1}$ School of Nursing, Tung Wah College, Homantin, Kowloon, Hong Kong, China \\ ${ }^{2}$ School of Nursing, The Hong Kong Polytechnic University, Hong Kong, China
}

Received: April 28, 2018

DOI: $10.5430 /$ jnep.v8n11p16

\author{
Accepted: June 3, 2018 \\ Online Published: June 7, 2018 \\ URL: https://doi.org/10.5430/jnep.v8n11p16
}

\begin{abstract}
Objective: Nursing students who participate in overseas placements are considered to have excellent opportunities to broaden their horizons and promote their personal and professional development. This study examines and compares nursing students' learning outcomes from their international experience in various countries.

Methods: This is a cross-sectional descriptive study. The study was conducted in a university that arranges overseas clinical placements for nursing students in pre-registration programmes. The participants were students in different years of study from a variety of nursing programmes. A questionnaire developed by the researchers, the International Education Survey was used to collect data.

Results: One hundred and forty-five valid questionnaires were collected. The students spent their summer overseas placement in a variety of countries, including the United Kingdom, United States, Japan, and mainland China. On a macro level, students benefitted from the experiences. For international perspective, the students who visited Japan gave the highest rating of 5.30 (SD $=0.51)$, while the score for China was among the lowest at $5.02(\mathrm{SD}=0.51)$. For personal development, the mean score was $4.58(\mathrm{SD}=0.84)$ for students who visited China, while the highest mean score was $5.16(\mathrm{SD}=0.54)$ for students who visited the US. For intellectual development, the lowest mean score was $4.45(\mathrm{SD}=0.97)$ for students who visited China, while those who visited the US gave the highest rating of $5.14(\mathrm{SD}=0.62)$. There was a significant difference in the scores for personal development between students who travelled to different countries, at $p<.05$. A chi-square test showed a significant association in international perspective between junior and senior students.

Conclusions: Demographics and country location influenced the students' overseas learning experience. Nurse educators are encouraged to use a reflective approach to help students to identity what they have gained from their placement, to maximize the value of their overseas experiences.
\end{abstract}

Key Words: International experience, Personal development, Nursing students, Overseas placement

\section{INTRODUCTION}

Hong Kong is a highly international city with a population of more than 7 million. ${ }^{[1]}$ It attracts a great deal of foreign investment, with the result that an increasing number of peo- ple from overseas are using the city's medical facilities. The users include employees of international corporations and their families, as well as visitors seeking medical treatment and health management options. The medical visits often

\footnotetext{
*Correspondence: Susan Ka Yee Chow; Email: susanchow@twc.edu.hk; Address: School of Nursing, Tung Wah College, 31 Wylie Road, Homantin, Kowloon, Hong Kong, China.
} 
relate to problems with adjusting to a new living and working environment, childbirth and pregnancy, and local communicable diseases. ${ }^{[2]}$

Within the healthcare discipline, nurses spend more time than other professionals providing care to patients, whether in hospital or community settings. Due to increasing internationalization, there is an immense need to build the capacity of future nurses having global perspectives to connect people with diverse cultures to be able to work effectively. Universities support the involvement of nursing students in overseas placement programmes, so that they will have a chance to experience different cultures through clinical placements in hospitals or study activities in universities. It is thought that nursing students who participate in an overseas placement will have excellent opportunities to broaden their horizons, promote their personal and professional development, and improve their interpersonal skills through communicating with people from a different culture. Cultural competence is considered crucial not only to prepare students to deliver culturally competent care to patients from different ethnic backgrounds, ${ }^{[3]}$ but also to enhance the image of the healthcare institution for which they work, in the area of patient services. Cultural competence education in nursing curricula consisted of prioritising the cultural factors that affect healthcare delivery, promoting optimum and high quality care to diverse patient population and being able to address social justice and healthcare disparities. ${ }^{[3]}$

An international clinical learning experience provides a unique opportunity for learners to visit and observe the nursing practices and healthcare systems of other countries. Nowadays, nursing students are increasingly aware of the opportunities that are available to go abroad to gain overseas experience, in addition to local experience. The most popular destinations for nursing students to gain international experience are Australia, New Zealand, Western Europe, South America, and Africa, while the places of least interest are Asia and North America. Africa, Central America, and Asia are attracting those students who prefer to acquire different experiences with vulnerable people. ${ }^{[4]}$ An integrated literature review suggests that the overall benefits for students who participate in these placements include professional growth, career and cognitive development, and cultural competence. ${ }^{[5]}$ Advanced nursing practice students in the Netherlands who specialized in psychiatric healthcare were able to broaden their global vision after participating in a one-week intensive exchange in the US. ${ }^{[6]}$ The valuable experience reported by paediatric nurses was having the opportunity to appreciate the children's rights stance promoted in other developing countries. ${ }^{[7]}$ Another study reinforced the positive value of international learning from its finding

Published by Sciedu Press that nursing students who participated in a study abroad experience showed greater self-awareness and self-confidence than their counterparts who had not participated in the programme. ${ }^{[8]}$ Nursing students who had the opportunity to participate in nursing visits to older people during an international student programme in Portugal learnt how to focus on the potential needs of clients and families and to use materials in rational ways. ${ }^{[9]}$ Other than increasing the students' knowledge about nursing practices and healthcare systems in other countries, the international experience in European countries improved the linguistic skills of the participating students, as most mainland European countries teach English as a second language. ${ }^{[10]}$

Studies have addressed the motivation of students who participate in international learning programmes to low-income countries. A qualitative study revealed that 'developing global awareness', 'global engagement', and 'global citizenship and social justice' were what went through the minds of the students when they first heard about the opportunity to travel to those low-income countries. For students with international experience in a developing country such as the Dominican Republic, their service learning experience had long-lasting effects. They were able to increase their knowledge about the prevalence of disease in a country with limited resources. ${ }^{[11]}$ Other than such immediate benefits as personal growth and cultural awareness, the meaningful experiences gained from their international programme had a long-term impact on the participants' professional lives, as they were able to apply their experiences to their nursing careers, resulting an increase in their ability to deliver culturally sensitive care. Most importantly, these experiences caused them to reach a higher level of critical thinking and to consider advocating for meaningful changes in the nursing profession. ${ }^{[12]}$ Nurse educators have come to understand that acquiring overseas experience not only helps students to acquire cultural competence but also enhances the development of broad intellectual, personal, and practical skills.

Despite the overall positive comment on international experience, a few studies revealed less desirable outcomes, which could be related to the diverse cultures of the countries, the characteristics of the population, and the quality of the mentorship during the courses. Students might experience difficulties adjusting to a new culture without immediate support from the school and a lack of preparation. ${ }^{[13-15]}$ The findings from the literature may not be representative enough to draw the conclusion that all nursing students are able to benefit from the immediate or long-term outcomes of international experience. A further inquiry involving an institution that offers international programmes in both developed and developing countries is warranted. A university in Hong Kong 
provided the financial and personnel resources to support pre-registered nursing students who were participating in an overseas placement in the summer for a duration of three to four weeks. The clinical placement scheme was arranged jointly with universities or hospitals in mainland China and overseas countries such as Japan, the US, and the UK. The programmes were arranged in countries where the academic staff of the university had contacts. Because the students participated in international experience programmes in diverse countries, it is imperative to evaluate their learning outcomes to provide additional justification for the effective allocation of resources for the programmes.

The aim of the paper was to examine and compare nursing students' learning outcomes from their international experience in various countries.

\section{Methods}

\subsection{Research design}

A quantitative cross-sectional design was used in this study.

\subsection{Setting}

The study was conducted in a university where overseas clinical placements were organized for the students.

\subsection{Sample and sampling}

Consecutive sampling was used in this study. All of the nursing students in a university who participated in an overseas placement programme in 2014 were invited to participate in the study. The students were enrolled in bachelor's degree, higher diploma, or master's degree (pre-registration) programmes. The overseas venues included hospitals in mainland China, the UK, the US, and Japan. The students who were unable to complete the entire course of the overseas experience were excluded from the study.

\subsection{Research instrument}

In addition to a questionnaire on demographics that was developed by the researchers, the International Education Survey (IES) developed by Zorn (1996) ${ }^{[16]}$ was used to examine the impact on the students of their learning experiences. The original IES consists of 30 items on a 7-point Likert scale, with $1=$ influenced me to a low/small degree and $7=$ influenced me to a high/large degree. The four domains of the IES examine the long-term impact, international perspectives, personal development, and intellectual development of the participants after their overseas experiences.

According to the author, international perspective investigates to the extent that international experience shaped and influenced students to evaluate world issues. For personal development, the questions focus on what degree has the international experience influenced on career decision and interpersonal relationships. While intellectual development examine whether the experiences enhanced the motivation and ability to learn a foreign language and the selection of reading materials. The alpha coefficient of the entire scale is 0.97 , while the coefficient of the four subscales ranges from 0.85 to 0.94 . The contents of the survey were reviewed by experts before the survey was administered. The same scale was used by other authors in $2000^{[17]}$ and in $2011^{[18]}$ to evaluate the experiences of students in various countries, including developing and developed countries. At the time of the study, none of the participants had embarked on their nursing careers; therefore, the section containing five items and two other items evaluating the long-term impact on the participants' professional career were removed. The remaining 22 items in three subscales were used in the present study. The three dimensions consisted of four to eleven questions. For 'International perspective', the sample question was 'To what extent has your overseas clinical placement experience enhanced your understanding of the health policies of other countries?'. For 'Professional development', the sample question was 'To what degree would you encourage all university students to participate in an overseas clinical placement?'. For 'Intellectual development', the sample question was 'To what extent has your overseas clinical placement experience enhanced your motivation to learn a foreign language after returning home?'. To ensure the cultural relevance of the scale, a test of content validity was conducted, with a group of experts evaluating the relevance and representativeness of each individual question. Some students were invited to give their comments on whether the questions were easily comprehensible and whether it was necessary to rephrase the item statements.

\subsection{Ethical considerations}

Approval to conduct the study was obtained from the research ethics committee of the participating university. The participants were provided with the opportunity to give their informed consent to participate in the study, and told that they could withdraw from the study at any stage without affecting their studies. Issues related to confidentiality, anonymity, and their volunteer status were explained to the participants.

\subsection{Data analysis}

The data were analysed using IBM SPSS Statistics for Windows, version 23 (IBM Corp, Armonk, NY). The students' demographic information, various personal attributes, and IES scores were examined using descriptive analysis. For comparisons between the scores from different countries, one-way ANOVA was used. An independent $t$-test was conducted to examine the learning outcomes of students who 
had travelled to developed and developing countries. A chisquare test was used to examine the association between the learning experiences of junior and senior students. $p<.05$ was set as the level of statistical significance in a two-tailed test.

\section{Results}

\subsection{Profile of the participants}

An overall response rate of $85.7 \%(n=145)$ was achieved. The majority of the students who participated were female (70.1\%). Most were aged 21-25 after they had completed their overseas experiences. Most $(73.1 \%)$ of the participants were enrolled in the bachelor's degree programme, $22.8 \%$ in the higher diploma programme, and $4.1 \%$ in the pre-registration master's degree programme. The students spent their summer overseas placement in a variety of countries, namely the UK, US, Japan, and mainland China. Most of the students $(81.4 \%)$ participated in a placement in China, and $10.3 \%$ in the UK. Table 1 shows the demographics of the students who participated in this study and the countries that they visited in their placement.

\subsection{IES scores of students with placements in different countries}

The summative mean, with a maximum score of 7.0 for each subscale with reference to the different countries, varied. For international perspective, the students who visited Japan gave the highest rating of $5.30(\mathrm{SD}=0.51)$, while the score for China was among the lowest, at $5.02(\mathrm{SD}=0.51)$. For personal development, the mean score was $4.58(\mathrm{SD}=0.84)$ for the students who visited China, with the highest mean score of $5.16(\mathrm{SD}=0.54)$ for the students who visited the United
States. For intellectual development, the lowest mean score was $4.45(\mathrm{SD}=0.97)$ for the students who visited China, while the students who visited the United States gave the highest rating of $5.14(\mathrm{SD}=0.62)$. The mean scores were above 4.5 out of 7.0 in the three domains of IES, regardless of the country that the students visited (see Table 2). Despite the variations in score in the three domains of IES, no significant differences in the three domains among the different countries were seen in the one-way ANOVA.

Table 1. Participants' demographics and countries visited

\begin{tabular}{ll}
\hline Demographic characteristics & $\mathbf{N ~ ( \% )}$ \\
\hline Gender & $43(29.7)$ \\
Male & $70.3(70.3)$ \\
Female & \\
Age & $17(11.7)$ \\
$<20$ years & $121(83.4)$ \\
$21-25$ years & $6(4.1)$ \\
26-30 years & $1(0.7)$ \\
$\geq 31$ years & \\
Study programme & $4(4.1)$ \\
Master's Degree (Pre-registration) & $106(73.1)$ \\
Bachelor's Degree & $33(22.8)$ \\
Higher Diploma & \\
Year of study & $3(2.1)$ \\
Year 1 & $82(58.6)$ \\
Year 2 & $56(38.6)$ \\
Year 3 & $4(2.8)$ \\
Year 4 & \\
Country visited & $118(81.4)$ \\
China & $6(4.1)$ \\
Japan & $15(10.3)$ \\
United Kingdom & $6(4.1)$ \\
United States &
\end{tabular}

Table 2. IES scores of students with placements in different countries

\begin{tabular}{llll}
\hline Country & International perspective & Personal development & Intellectual development \\
\hline China & & & $4.41(0.99)$ \\
Mean (SD) & $4.98(0.80)$ & $4.59(0.84)$ & 6.50 \\
Maximum & 7.00 & 6.33 & 1.00 \\
Minimum & 2.67 & 1.42 & $5.42(0.63)$ \\
United States & & & 6.25 \\
Mean (SD) & $5.28(0.57)$ & $5.17(0.54)$ & 4.50 \\
Maximum & 6.00 & 6.00 & $4.62(0.88)$ \\
Minimum & 4.33 & 4.58 & 5.72 \\
United Kingdom & & & 6.5 \\
Mean (SD) & $5.30(0.64)$ & $5.03(0.63)$ & $4.46(1.27)$ \\
Maximum & 6.83 & 6.50 & 6.00 \\
Minimum & 4.00 & 4.00 & 2.25 \\
Japan & & $4.83(0.63)$ & 5.67 \\
Mean (SD) & $5.31(0.51)$ & 3.75 & \\
Maximum & 5.83 & 4.50 & \\
Minimum & &
\end{tabular}


3.3 The characteristics of the countries and the three dif- $t$-test was conducted to compare differences in the students' ferent dimensions of IES

The countries were further categorized into developing country and developed countries to provide an in-depth understanding of the students' learning outcomes. The developed countries were the UK, US, and Japan, while China was categorized as a developing country. An independent samples learning outcomes between the developed countries and the developing country in the three domains of IES. There was a significant difference in the scores for personal development, at $p<.05$, a difference approaching significance for international perspective. Please refer to Table 3 for details.

Table 3. The characteristics of the countries and the three different dimensions of IES

\begin{tabular}{lllll}
\hline & Developing country & Developed countries & $\boldsymbol{t}$ & $\boldsymbol{p}$ value \\
\hline International perspective & $4.99(0.810)$ & $5.29(0.568)$ & -1.885 & .061 \\
Personal development & $4.59(0.841)$ & $5.01(0.601)$ & -2.467 & $.015^{*}$ \\
Intellectual development & $4.42(0.998)$ & $4.75(0.96)$ & -1.604 & .11 \\
\hline
\end{tabular}

${ }^{*} p<.05$

\subsection{Differences between junior and senior students}

A chi-square test of independence was performed to examine the association between junior and senior students on the individual items of IES. The Year 1 and Year 2 students were combined under the category of junior nursing students $(\mathrm{n}=$ 85), while the Year 3 and Year 4 students were categorized as senior students $(n=60)$. Among the different categories of students, a significant association was found between 'enhanced my understanding of other cultures', 'enhanced my understanding of the health policies of other countries', 'influenced my understanding of nursing and healthcare in other countries', 'increased the likelihood that I will practise nursing in another country' and 'facilitated my ability to consider international aspects in social activities'. The junior and senior year students were considered independently of each another with regard to the above variables of IES. Please refer to Table 4 for details.

Table 4. The association between junior and senior year students with regard to specific items of IES

\begin{tabular}{|c|c|c|c|c|}
\hline \multirow[b]{2}{*}{ Specific items of IES } & \multicolumn{2}{|l|}{ Year } & \multirow{2}{*}{$\begin{array}{l}\chi^{2} \text { test of } \\
\text { independence }\end{array}$} & \multirow[b]{2}{*}{$p$ value } \\
\hline & $\begin{array}{l}\text { Junior } \\
\text { Total count }\end{array}$ & $\begin{array}{l}\text { Senior } \\
\text { Total count }\end{array}$ & & \\
\hline Enhanced understanding of other culture & 85 & 60 & $20.06(5)$ & $.001^{*}$ \\
\hline Enhanced understanding of health policy of other country & 85 & 60 & $9.816(4)$ & $<.05^{*}$ \\
\hline Influenced understanding of nursing and healthcare in other countries & 84 & 59 & $9.418(4)$ & .05 \\
\hline Increased the likelihood to practice nursing in other country & 84 & 59 & $12.401(6)$ & .05 \\
\hline Facilitated an international considerations in social activities & 85 & 60 & $16.976(6)$ & $.009 *$ \\
\hline
\end{tabular}
${ }^{*} p<.05$

\section{Discussion}

The results of our study showed that students benefited from participating in an overseas clinical placement, as indicated in the IES subscales showing that no overall score fell below the neutral score of 4 . At a macro level, the learning outcomes of the nursing students' international experiences were considered to be effective. However, notable differences were seen between the outcomes of students who participated in the developed countries and the developing country, and between those of the junior and senior students. For the students who went to developed countries, they were able to benefit more from the experience. The junior students showed better increase of understanding of other culture than their counterparts after international education.

There have been previous studies on the international learning experiences of nursing students in developed and developing countries. The findings of our study differ from the findings of those studies. A study in 1998 observed similar experiences from students $(n=14)$ who travelled to developed countries, while those who went to developing countries such as the Dominican Republic and Nicaragua, which have poor resources for patient care, reported having a most rewarding lived experience that connected them with the essence of nursing. ${ }^{[19]}$ The above findings were corroborated in a later study, which found that nursing students who had gone on international programmes to developing coun- 
tries gained more from their experiences than their counterparts who went to developed countries. ${ }^{[17]}$ Nursing students from western countries reported that international experience could certainly support their development of cultural sensitivity and increase their adaptability and tolerance in culturally diverse contexts. ${ }^{[19]}$ In United Kingdom, students reported the clinical experiences in their home institution were overprotected, the opportunities to less developed countries provided them with unique experiences to test out their independence and confidence. ${ }^{[20]}$ In our study, the nursing students who went to China scored lower in the three dimensions than those who travelled to UK, US, and Japan. In many ways, China is both a developed and developing country. What makes China a developing country is that the majority of the Chinese people live in poverty. ${ }^{[21]}$ On the other hand, in Gross Domestic Product (GDP), China ranked second in 2018, just below the US and above the UK, according to the World Bank. ${ }^{[22]}$ Beijing, Hangzhou, Shanghai, and cities around the eastern coast of the country are affluent cities in terms of GDP, prices, population, and so on. ${ }^{[23]}$ Moreover, cities in China are in fact divided into four tiers based on indicators such as commercial resources, the city's pivotability, and varieties of lifestyle. ${ }^{[24]}$ In our study, arrangements were made for the majority of students to have placements in a variety of hospitals located in first or second-tier cities. Their exposure to a developing country was minimized, as opportunities to interact effectively with vulnerable ethnic groups were reduced. In addition, in language and cultural background, those affluent cities in mainland China are fairly monocultural and less varied than Western countries. The nursing students who went to mainland China might have found the experience less exciting than those who went elsewhere, as their cultural experiences in terms of international perspective were not as rich as those who went to the other countries, causing them to accord lower scores to their experiences. Having the students visit a mix of countries during their course of study could lead to better learning outcomes from overseas placements.

Hong Kong is a part of China that is governed under the concept of 'One Country, Two Systems' as enacted by the Basic Law. ${ }^{[25]}$ Nursing students in Hong Kong are bilingual, as they speak Mandarin and Cantonese, but read textbooks from Western countries. While opportunities are available for overseas placements in developed and developing countries, our results indicated that not all of the placement experiences were found to been beneficial to the students' personal development. If the intention is for overseas experiences to stimulate the students into reflecting on their own ethnicity and to promote communication, the students should be exposed to a variety of cultural experiences outside of their own country. In order to broaden students' horizons and to prompt them to make comparisons between cultures, educational institutions should give students the opportunity to have challenging experiences that will cause them to become aware of different social and political structures, which will stimulate personal development and growth. ${ }^{[26]}$ To improve the overseas experience, theoretical considerations as well as previous networks need to be taken into consideration. It is preferable for the overseas experiences and chosen countries to differ from that of the student's own country in the following ways: it should be composed of a different ethnic group or have a mixed ethnic composition, it should have a population that speaks a different language, and it should have a different healthcare system. Only under this theoretical underpinning will the overseas experience influence the students in their career choices, raise their level of confidence, cause them to learn to be more tolerant of other ethnic groups, and influence the way that they judge themselves in relation to other populations. ${ }^{[16]}$ Due to the varied nature of the overseas experiences offered in university, it is suggested that junior students have placements in countries that speak the same language as themselves, to ease the difficulties of communication. ${ }^{[27]}$ For senior year students, the overseas experiences should be designed to enhance their ability not only to experience the life practices of the host country, but also to compare and contrast the historical, economic, and political influences on the health values and healthcare system of the host country with those of their own country.

Regarding the comparison between junior and senior year students on specific experiences, our results showed that junior students enjoyed and benefited more than the senior students from understanding the culture, nursing practices, and health policies of other countries. Obviously, demographic and academic characteristics are influencing the experiences of this population of students. The university education in Hong Kong consists of a number of courses on General Education; most of these courses are non-disciplinary in nature and are aimed at broadening the students' horizons to achieve personal growth and development. The courses include computing, arts, business, social science, cultural and world views, language, history, science and human nature, and so on. The bachelor's degree students are required to take several general education subjects during a five-year study period. ${ }^{[28]}$ By the time that the students have completed the academic requirements and met the academic demands, the expectation for international experience may not have been met. A recent study suggested that encouraging engagement in extracurricular activities and cultural education was the most influential factor in increasing the cultural competence of nursing students. ${ }^{[29]}$ The above results imply that encouraging students 
to participate in extracurricular activities and to have constant contact with those from other cultures could be an alternative to engaging in overseas experiences. If the senior students had already engaged in such cultural activities before taking part in the international experiences, they might not have been able to obtain additional benefits from their overseas travel unless the placements had been specially designed and adequately planned to challenge their initial perceptions of the culture. Moreover, after completing their overseas programmes, students need to undergo a de-briefing session with nurse educators to scrutinize their overseas learning using a reflective approach. Other reflective activities such as writing a reflective journal could further help the students to identity their own unique thoughts, and ensure that their overseas experiences are of value. Nurse educators could further explore the hospital learning environment and the quality of the students' mentorships, to get a deeper understanding of the students' learning experiences and to identify correlations between student satisfaction, learning outcomes, and the social climate of the clinical learning environment.

\section{Limitations of the study}

One shortcoming of this study is the findings cannot be generalized though the results provided broader insight into the experience of international experience. Another limitation is the data were collected from one university with one cohort year of students. Using multiple sources of information such as qualitative interviews could also have enhanced the credibility of the information that was collected.

\section{Conclusion}

In summary, a globalizing world means that, more than ever before, people are moving around and relocating to different areas of the world. The need for nurses to be aware of global diversity and different healthcare systems is considered essential to preparing future leaders in local and international settings. Having an opportunity to gain international experience during their studies has a deep impact on the professional and personal growth of nursing students. The learning outcomes from overseas placements depend very much on the country of origin of the students and where the experiences take place. This study presented findings that contrast with those of previous studies. The demographic and academic characteristics of the students influenced their overseas learning experiences. This study raises sensitive questions about overseas learning in a developing country and how nurse educators can help students to reflect on their experiences to meet their expectations.

\section{ACKNOWLEDGEMENTS}

The authors are grateful to all of the nursing students who participated in this study after their overseas clinical placement programme.

\section{Conflicts of Interest Disclosure}

The authors declare that they have no conflicts of interest relating to the publication of this article.

\section{REFERENCES}

[1] Sassen S. The global city: strategic site, new frontier. In Moving Cities-Contested Views on Urban Life. Springer VS Wiesbaden; 2018. 11-28 p.

[2] Choi JS, Kim JS. Effects of cultural education and cultural experiences on the cultural competence among undergraduate nursing students. Nurse Educ in Pract. 2018 Mar 31; 29: 159-62. PMid:29360621 https://doi.org/10.1016/j.nepr. 2018.01 .007

[3] Lin CJ, Chang PR, Wang LH, et al. Cultural competence course for nursing students in Taiwan: A longitudinal study. Nurse Edu Today. 2015 Dec 1; 35(12): 1268-74.

[4] Kent-Wilkinson A, Leurer MD, Luimes J, et al. Studying abroad: Exploring factors influencing nursing students' decisions to apply for clinical placements in international settings. Nurse Edu Today. 2015 Aug 1; 35(8): 941-7.

[5] Kelleher S. Perceived benefits of study abroad programs for nursing students: An integrative review. J Nurs Edu. 2013 Nov 18; 52(12): 690-5. PMid:24256000

[6] Maas LG, Ezeobele IE. Reflections from Dutch advanced nursing practice students on psychiatric mental healthcare in the United States.
Arch Psychiatr Nurs. 2014 Dec 1; 28(6): 357-61. PMid:25457683 https://doi.org/10.1016/j.apnu . 2014.08.008

[7] Standage R, Randall D. The benefits for children's nurses of overseas placements: where is the evidence? Issues Compr Pediatr Nurs. 2014 Jun 1; 37(2): 87-102. PMid:24495156 https ://doi .org/10 . 310 9/01460862.2014.880531

[8] Long T. Influence of international service learning on nursing students' self efficacy towards cultural competence. J Cultur Divers. 2016 Mar 1; 23(1).

[9] Silva Leite B, Alves dos Santos W, Cavalcanti Valente GS, et al. Nursing consultations for the elderly in primary care in international student exchange experience report. Journal of Nursing UFPE/Revista de Enfermagem UFPE. 2016 Sep 2; 10.

[10] Cowan RB. An appraisal of European exchange programmes for nursing students. Nurs Stand (through 2013). 2007 Feb 7; 21(22): 40

[11] Axley L. Nursing in diverse cultures: an international experience. Tennessee Nurse. 2009; 72(1): 4-5.

[12] Evanson TA, Zust BL. "Bittersweet knowledge": the long-term effects of an international experience. J Nurs Edu. 2006 Oct 1; 45(10): 412-20.

[13] Koskinen L, Tossavainen K. Study abroad as a process of learning intercultural competence in nursing. Int J Nurs Pract. 2004 Jun 1; 10(3): 
111-20. PMid: 15149458 https://doi.org/10.1111/j.1440-1 $72 \mathrm{X} .2004 .00470 . \mathrm{x}$

[14] Sandin I, Grahn K, Kronvall E. Outcomes of Swedish nursing students' field experiences in a hospital in Tanzania. J Transcult Nurs. 2004 Jul; 15(3): 225-30. PMid:15189644 https://doi .org/10.1 $177 / 1043659604265122$

[15] Jenkins E, Balneaves LG, Lust AL. Students and international nursing shock. Can Nurse. 2011 Sep 1; 107(7): 26-30.

[16] Zorn CR. The long-term impact on nursing students of participating in international education. J Prof Nurs. 1996 Mar 1; 12(2): 106-10. https://doi.org/10.1016/S8755-7223(96)80056-1

[17] Thompson K, Boore J, Deeny P. A comparison of an international experience for nursing students in developed and developing countries. Int J Nurs Stud. 2000 Dec 1; 37(6): 481-92. https: //doi.org/10.1016/S0020-7489(00)00027-4

[18] Smith K, Curry K. Is it worth it? Measuring the long-term effects of an international experience for nursing students in Ecuador. $\mathrm{J}$ Community Heal Nurs. 2011 Jan 31; 28(1): 14-22. PMid:21279886 https://doi.org/10.1080/07370016.2011.539080

[19] Crossman JE, Clarke M. International experience and graduate employability: stakeholder perceptions on the connection. High Educ. 2010 May 1; 59(5): 599-613. https ://doi.org/10.1007/s107 34-009-9268-z

[20] Lee NJ. The impact of international experience on student nurses' personal and professional development. Int Nurs Review. 2004 Jun 1; 51(2): 113-22. PMid:15102116 https://doi .org/10.1111/j. $1466-7657.2003 .00200 . x$

[21] Is China a developed country? [Internet]. China: ChinaPower Project. [cited 2018 March 23]. Available from: https://chinapower.c sis.org/is-china-a-developed-country/
[22] All countries and economies-GDP. Data - World Bank. [Internet]. [cited 2018 March 20]. Available from: https://data. worldbank.org/indicator/NY. GDP. MK TP. CD? end $=2013 \&$ start $=2005 \& y e a r \_h i g h \_d e s c=t r u e$

[23] Four cities played outside role in Chinese economy [Internet]. Hong Kong: South China Morning Post. [cited 2018 April 27]. Available from: http://www.scmp.com/news/china/economy/articl e/2130079/four-cities-played-outsize-role-chinese -economy

[24] Top 15 'new first-tier' cities in China [1]- Chinadaily.com.cn [Internet]. China: Chinadaily. [cited 2018 March 20]. Available from: http://www.chinadaily.com.cn/business/2017top 10/2017-05/15/content_29343927.htm

[25] Enactment of the "One Country, Two Systems" Concept [Internet]. Hong Kong: Basic Law. [cited 2018 April 25]. Available from: http://www.basiclaw.gov.hk/en/publications/bo ok/15anniversary_reunification_ch1_3.pdf

[26] Lee RL, Pang SM, Wong TK, et al. Evaluation of an innovative nursing exchange programme: health counselling skills and cultural awareness. Nurse Educ Today. 2007 Nov 1; 27(8): 868-77.

[27] DeDee LS, Stewart S. The effect of student participation in international study. J Professional Nurs. 2003 Jul 1; 19(4): 237-42. https://doi.org/10.1016/S8755-7223(03)00086-3

[28] General Education Centre-The Hong Kong Polytechnic University. [Internet]. Hong Kong: General Education Centre. [cited 2018 February 14]. Available from: http://www.polyu.edu.hk/ gec/ind ex.php

[29] Choi JS, Kim JS. Effects of cultural education and cultural experiences on the cultural competence among undergraduate nursing students. Nurse Educ Pract. 2018 Mar 31; 29: 159-62. PMid:29360621 https://doi.org/10.1016/j.nepr.2018.01.007 